\title{
Malaria in the USA: How Vulnerable Are We to Future Outbreaks?
}

\author{
Kyndall C. Dye-Braumuller ${ }^{1}$ [D $\cdot$ Mufaro Kanyangarara $^{2}$
}

Accepted: 18 December 2020 / Published online: 14 January 2021

(C) The Author(s), under exclusive licence to Springer Nature Switzerland AG part of Springer Nature 2021

\begin{abstract}
Purpose of Review Malaria poses a threat to nearly half of the world's population, and recent literature in the USA is lacking regarding understanding risk for local outbreaks. This article aims to review Anopheles mosquito data, vector-borne disease outbreak preparedness, and human travel data from large international gateway cities in an effort to examine risk for localized outbreaks.

Recent Findings The majority of vector control organizations are widely unprepared for a vector-borne disease outbreak, and multiple mosquito species capable of transmitting malaria continue to persist throughout the USA.

Summary Despite the lack of recent autochthonous cases in the USA, multiple risk factors suggest that local malaria outbreaks in the USA will continue to pose a public health threat due to large numbers of international travelers from endemic areas, multiple Anopheles spp. capable of transmitting the parasite, and unsatisfactory vector-borne disease outbreak preparedness. Climate conditions and recent changes in travel patterns will influence malaria across the globe.
\end{abstract}

Keywords Malaria $\cdot$ Plasmodium $\cdot$ USA $\cdot$ Locally acquired $\cdot$ Preparedness

\section{Introduction}

Human malaria is one of the most ubiquitous and prevalent human infectious diseases around the world. This acute febrile illness is caused by protozoan intracellular obligate parasites in the genus Plasmodium (Haemosporida: Plasmodiidae) and vectored by mosquitoes in the genus Anopheles (Diptera: Culicidae) [1]. Five species of Plasmodium cause disease in humans: $P$. vivax, $P$. falciparum, $P$. malariae, $P$. ovale, and $P$. knowlesi $[1,2]$. Tertian malaria caused by both $P$. falciparum and $P$. vivax is the largest threat globally. However, $P$. falciparum, found throughout the tropics, is the deadliest of all Plasmodium species, causing the most severe disease and death. Children less than 5 years of age and pregnant women are at the highest risk for contracting malaria and

This article is part of the Topical Collection on Emerging Vector Borne Diseases in the U.S.

Kyndall C. Dye-Braumuller

kyndallb@email.sc.edu

1 Laboratory of Vector-Borne and Zoonotic Diseases, Arnold School of Public Health, University of South Carolina, Columbia, SC, USA

2 Department of Epidemiology and Biostatistics, Arnold School of Public Health, University of South Carolina, Columbia, SC, USA developing severe disease [1-4]. Given the geographic distribution of Plasmodium species, anyone residing in or traveling to Sub-Saharan Africa, Southeast Asia, Eastern Mediterranean, Western Pacific, and the Americas is at risk for malaria - representing nearly half of the world's population $[3,4]$. Malaria exacts a devastating toll on Sub-Saharan Africa, which accounts for about $90 \%$ of malaria cases and $94 \%$ of malaria deaths globally [3].

Formerly endemic in temperate regions of the United States (USA), malaria was successfully eliminated in the early 1950s after the establishment of the Office of Malaria Control in War Areas - the precursor to the Centers for Disease Control and Prevention (CDC). Improved sanitation and medical care, technological advances, and widespread insecticide use led to the successful interruption of malaria transmission [5-9]. Although endemic transmission of the parasite was eliminated, competent Anopheles vectors still exist in the USA. An. quadrimaculatus Say and An. freeborni Aitken are historically recognized as the major malaria vectors in the eastern and western USA, respectively [1]. Additional competent vectors in the USA include An. punctipennis (Say), An. albimanus Wiedemann, An. pseudopunctipennis Theobald, members of the An. quadrimaculatus complex (An. quadrimaculatus, An. diluvialis, An. inundatus, An. maverlius, and An. smaragdinus), and members of the An. crucians Wiedemann complex (An. crucians, An. bradleyi, and An. georgianus) [1, 
10-12]. Several of these USA-indigenous vectors have been implicated in sporadic local outbreaks of malaria [1, 13-17]. From 1957 to 2003, 63 malaria outbreaks occurred in the USA and were associated with infected individuals traveling to the USA from malaria-endemic areas [4].

Malaria is a nationally notifiable disease, and the CDC publishes state-level malaria case data annually for the USA. Over the past few decades, the average number of malaria cases reported to the CDC has steadily increased. Based on the most recent and available annual malaria surveillance reports (2011, 2012, 2014-2016), an average of 1773 malaria cases are reported in the USA each year [4, 18-21]. In 2016, a total of 2078 cases were reported, the highest number of malaria cases since 1972 [4]. The top ten states with the highest numbers of malaria cases (over the previously mentioned years 2011, 2012, 2014-2016) accounting for $64.1 \%$ of the case burden were New York (296.4 cases annually on average), Maryland (147.4 cases), California (118.2 cases), Texas (115.6 cases), New Jersey (91.6 cases), Georgia (77.6 cases), Virginia (77.4 cases), Florida (77.0 cases), Massachusetts (75.2 cases), and Pennsylvania (73.6 cases) [4, 18-21].

An overwhelming majority $(98.8 \%)$ of malaria cases are imported, or acquired outside of the USA or its territories [4]. Sub-Saharan Africa is reported as the country of origin for $75.0 \%$ of imported cases where country of origin is known. Although all five human Plasmodium species have been documented in American citizens returning from abroad, $P$. falciparum and $P$. vivax represent $61.9 \%$ and $15.1 \%$ of malaria cases identified respectively [4, 18-21]. P. knowlesi malaria has only once been imported into the USA since its discovery; it was reported in a traveler from the Philippines in 2008 [22, 23]. No autochthonous or indigenous malaria cases were reported in the USA between 2011 and 2016. However, there were 6 cases of cryptic, or unexplained exposure, for which epidemiologic investigations were unable to identify plausible exposures for cases [4]. Although it has never been documented in the USA, a rare but possible source of disease in non-endemic regions is airport malaria [24•]. Airport malaria occurs when an infective Anopheles mosquito is transported on aircraft or via baggage from a malariaendemic area $[24 \bullet, 25,26]$.

Congenital malaria, caused by Plasmodium transmission from mother to child during pregnancy or perinatally during labor, is another risk for women of child-bearing age. Between 2011 and 2016, a total of 8 congenital cases of malaria were reported: 2 cases in 2011, 2 cases in 2012, 1 case in 2014, 1 case in 2015, and 2 cases in 2016 [4, 18-21]. Although travel from an endemic area was confirmed within the prepartum period for all cases, all babies acquired the infection within the USA.

Despite the relative unlikelihood of locally transmitted malaria occurring in the USA, the potential threat of the introduction and establishment of local malaria transmission remains a public health concern. The likelihood of local transmission of malaria being established depends on the availability of competent vectors, the suitability of climatic and environmental conditions for the development and survival of the malaria vector and parasite, and vector susceptibility to infection with Plasmodium [27]. With increasing globalization, trade, and large volumes of international travel, there is a paucity of research investigating the risk for malaria transmission in larger commerce or travel gateways in the USA. Much of the recent literature on malaria in the USA focuses on treatment regimens and the economic impact of treatment [28-30]. The goal of this review was to describe the potential risk for localized outbreaks of malaria in the USA in the context of the distribution of indigenous Anopheles species, human travel patterns and population dynamics, and the preparedness of local and state vector control programs.

\section{Recent Autochthonous Malaria in the USA}

Since 2000, four outbreaks of autochthonous malaria transmission have been documented in the USA. The most recent outbreak occurred in Palm Beach County, Florida, in 2003. Although no collected Anopheles tested positive for Plasmodium, both An. quadrimaculatus and An. crucians were collected throughout the county and implicated as probable vectors [17]. All seven cases of malaria identified during this outbreak had the same strain of $P$. vivax. Investigators determined that international travelers and immigrantsincluding migrant workers from Mexico-were the most likely source of infection [17]. Florida is particularly vulnerable to outbreaks of malaria due to densely populated cities, the increasing number of international travel ports, favorable environmental and climatic conditions for parasite development and survival, and established Anopheles populations [15].

In 2002, in Loudoun County, Virginia, three adolescents were diagnosed with $P$. vivax malaria $[13,27]$. An. quadrimaculatus and An. punctipennis from both Loudoun County and neighboring counties tested positive for $P$. vivax. This was the first collection of Plasmodium-positive mosquitoes in conjunction with human malaria cases in the USA since the national malaria surveillance system began in 1957 [13, 27]. Given the distance from the nearest international airport to all patient homes exceeded $10 \mathrm{mi}$, the CDC concluded that local Anopheles mosquitoes likely became infected after feeding on a malaria-infected person in the general vicinity [13]. Two additional instances of locally acquired $P$. vivax malaria were reported in the early 2000s: one in Suffolk County, NY, and the other in Detroit, MI [14, 16]. In both instances, local collections of An. quadrimaculatus and An. punctipennis tested negative for Plasmodium. As international airports were too distant from the presumed sites of infection and both infected persons had no significant travel 
history, the CDC declared both instances locally acquired [14, 16]. Although there have not been any autochthonous malaria cases in the USA since 2003, the continued risk for local transmission underscores the need for ongoing malaria surveillance and the strengthening of local and state health department capacity for outbreak preparedness and response.

\section{Distribution of Anopheles spp. Capable of Transmitting Malaria}

To ascertain the distribution of Anopheles spp. in the USA, data was obtained from MosquitoNET, a national database created by the $\mathrm{CDC}$ to collect and store mosquito surveillance and insecticide resistance data from Epidemiology and Laboratory Capacity (ELC) program recipients from across the nation. Although not all mosquito and vector control organizations report to the database, the data gives an indication of the presence and distribution of mosquito species in some areas of the USA. Individuals from three Florida counties which do not report to MosquitoNET provided personal communication to assist us in ascertaining Anopheles spp. collection information. To date, Anopheles mosquitoes have been reported by 32 states and 1 US territory. Of the multiple Anopheles species identified in each state, at least one is capable of vectoring malaria (Table 1) (CDC, unpublished data). As each county/state is not required to report surveillance data to MosquitoNET, and levels of surveillance capabilities and resources vary, it is difficult to compare across counties or states. Of the 32 states reporting Anopheles spp. capable of vectoring malaria, 12 have international airports ranked in the top 40 US passenger gateways to the world [31]. Reported Anopheles spp. in the counties housing the international airports were evaluated where data was available (Table 2). Understanding international traffic through international gateways is crucial as imported malaria could give rise to autochthonous transmission when local Anopheles species feed on malarious individuals who traveled to the USA. $A n$. quadrimaculatus and An. punctipennis, which are both capable of vectoring Plasmodium, are the most commonly reported Anopheles species in these counties. These findings agree with historical and published geographical distributions for both species $[10,11,32]$. Although data is missing from counties housing some of the largest airports including those in California, New York, and Massachusetts, based on the previously published geographical distributions of Anopheles spp., it is likely that malaria-vectoring capable species breed in the surrounding areas $[10,11,32]$. For airports in New York City (JFK, EWR, and LGA), three competent species: An. punctipennis, An. quadrimaculatus complex, An. crucians complex are likely to be present. In areas surrounding California international airports (LAX, SFO, OAK, SJC), both $A n$. freeborni and An. punctipennis are likely to be present. Notably, San Diego airport (SAN) may be too far south for either of these species to establish based on historical reports of species distributions. In Massachusetts, $A n$. punctipennis and An. quadrimaculatus are likely to occur in areas surrounding Boston airport (BOS).

\section{Preparedness for Mosquito-Borne Disease Outbreaks}

In 2017, a national survey, the first of its kind, evaluated the preparedness of mosquito control agencies for mosquitoborne virus outbreaks in the USA [33••]. Although the survey targeted arbovirus preparedness parameters, the results also translate to preparedness capacity for malaria outbreaks. Based on the standards for competency developed by the $\mathrm{CDC}$ and the American Mosquito Control Association (AMCA), only $8 \%$ of the 1083 mosquito control organizations that responded to the survey were classified as "fully capable," i.e., meeting all core and supplemental competencies for vector control outlined in the survey [33••]. Most $(84 \%)$ were classified as in need of improvement in at least one core competency. Of the five core competencies assessed, routine standardized mosquito surveillance (including species identification, abundance, and spatial distribution within a geographic area) is arguably the most important for malaria outbreak preparedness. About half $(46 \%)$ of organizations did not perform routine standardized mosquito surveillancepotentially a weak point in identifying malaria vectors and detecting potential outbreaks [33・•]. Entomological surveillance capacity across the country has declined in recent years, and this gap was particularly evident during the Zika outbreak in 2015-2016 [34, 35]. At a state level, 18 states had no vector control programs which met all core competencies, indicating that all of the programs in those states need improvement in vector-borne disease outbreak preparedness (Table 3) [33••]. The states rated as "needs improvement" were Alaska, Arkansas, Colorado, Connecticut, Iowa, Kansas, Kentucky, Maine, Maryland, Mississippi, Missouri, Nebraska, Pennsylvania, Rhode Island, South Carolina, South Dakota, Vermont, and West Virginia. Two of the states, Colorado and Pennsylvania, have large international airports within the top 40 major gateway cities to the world, reflecting potential high vulnerability and low preparedness for malaria outbreaks based on these combined factors.

\section{Discussion}

Although impossible to predict future locally acquired malaria outbreaks in the USA, there are certain risk factors which seemingly influence vulnerability. Based on the review of past autochthonous cases, the influx of malaria-infected 
Table 1 ELC-participating states reporting Anopheles spp. to MosquitoNET (January, 2016July, 2020) and from personal communication

\begin{tabular}{|c|c|c|c|c|c|}
\hline State & $\begin{array}{l}\# \\
\text { counties }\end{array}$ & $\begin{array}{l}\text { \# counties } \\
\text { reporting } \\
\text { Anopheles }\end{array}$ & $\begin{array}{l}\% \text { counties } \\
\text { reporting } \\
\text { Anopheles }\end{array}$ & $\begin{array}{l}\text { \# counties with } \\
\text { malaria vectors }\end{array}$ & $\begin{array}{l}\% \text { counties with } \\
\text { malaria vectors }\end{array}$ \\
\hline $\mathrm{AL}$ & 67 & 10 & 14.93 & 7 & 10.45 \\
\hline $\mathrm{AR}$ & 75 & 27 & 36.00 & 21 & 28.00 \\
\hline $\mathrm{CO}$ & 64 & 1 & 1.56 & 1 & 1.56 \\
\hline DC* & 1 & 1 & 100.00 & 1 & 100.00 \\
\hline FL & 67 & 10 & 14.93 & 10 & 14.93 \\
\hline GA & 159 & 142 & 89.31 & 135 & 84.91 \\
\hline IA & 99 & 30 & 30.30 & 30 & 30.30 \\
\hline ID & 44 & 3 & 6.82 & 2 & 4.55 \\
\hline IL & 102 & 1 & 0.98 & 1 & 0.98 \\
\hline IN & 92 & 65 & 70.65 & 65 & 70.65 \\
\hline $\mathrm{KS}$ & 105 & 3 & 2.86 & 3 & 2.86 \\
\hline KY & 120 & 27 & 22.50 & 25 & 20.83 \\
\hline MD & 23 & 12 & 52.17 & 12 & 52.17 \\
\hline MI & 83 & 21 & 25.30 & 21 & 25.30 \\
\hline $\mathrm{MN}$ & 87 & 1 & 1.15 & 1 & 1.15 \\
\hline MO & 114 & 42 & 36.84 & 41 & 35.96 \\
\hline MS & 82 & 52 & 63.41 & 52 & 63.41 \\
\hline $\mathrm{NC}$ & 100 & 23 & 23.00 & 23 & 23.00 \\
\hline $\mathrm{NE}$ & 93 & 34 & 36.56 & 32 & 34.41 \\
\hline NJ & 21 & 7 & 33.33 & 7 & 33.33 \\
\hline NM & 33 & 10 & 30.30 & 1 & 3.03 \\
\hline $\mathrm{OH}$ & 88 & 79 & 89.77 & 79 & 89.77 \\
\hline $\mathrm{OK}$ & 77 & 1 & 1.30 & 1 & 1.30 \\
\hline PA & 67 & 63 & 94.03 & 60 & 89.55 \\
\hline RI & 5 & 5 & 100.00 & 5 & 100.00 \\
\hline $\mathrm{SC}$ & 46 & 24 & 52.17 & 24 & 52.17 \\
\hline SD & 66 & 10 & 15.15 & 8 & 12.12 \\
\hline $\mathrm{TN}$ & 95 & 46 & 48.42 & 45 & 47.37 \\
\hline $\mathrm{TX}$ & 254 & 31 & 12.20 & 29 & 11.42 \\
\hline WA & 39 & 2 & 5.13 & 2 & 5.13 \\
\hline WI & 72 & 4 & 5.56 & 4 & 5.56 \\
\hline WV & 55 & 29 & 52.73 & 29 & 52.73 \\
\hline GU** & 1 & 1 & 100.00 & Unknown & Unknown \\
\hline
\end{tabular}

*DC: Although DC is not technically a state, it is regarded as such as with a single county in this database

**GU: Guam, US territory and has no counties - thus it is regarded as one large county due to its small size individuals (or imported malaria) from travelers, the presence of Anopheles spp. capable of transmitting Plasmodium, climate and environmental conditions, and vector-borne disease outbreak preparedness all play roles in this vulnerability. With the exception of climatic and environmental data, data on these risk factors were compiled for the 50 states in Table 3. The presence of Anopheles spp. was used as a proxy for climate and environmental conditions for mosquitoes as Plasmodium cannot be transmitted in the absence of favorable conditions such as relatively high temperatures (ideal temperature at $27^{\circ} \mathrm{C}$ ) and humidity (ideal relative humidity at $80 \%$ ) [9]. Eight of the ten states with the highest malaria case burdens also host millions of passengers in their international airports. New Jersey and Virginia are the only two states with the highest malaria case burden without international airports in the top 40; however, these states are near other airports on the list (IAD, JFK, EWR, and LGA). In addition, except for California, every state with international airports in the top 40 reported at least 3 Anopheles spp. capable of transmitting malaria. The remaining states that reported 3 or more malariavectoring species are located in the east of the country, especially the southeast which is warmer. Interestingly, six of the states with the highest malaria case burden received poor NACCHO rank of 3 or below for vector-borne disease 
Table 2 Gateway cities and reported Anopheles spp. within each county (data from year-end June 2019)

\begin{tabular}{|c|c|c|c|c|c|}
\hline State & Gateway city & County & $\begin{array}{l}\text { Major } \\
\text { airport }\end{array}$ & $\begin{array}{l}\text { Airport } \\
\operatorname{rank}^{\dagger}\end{array}$ & Malaria vector species reported \\
\hline FL & Miami & Miami-Dade & MIA & 3 & An. quadrimaculatus, An. crucians $^{\dagger \dagger}$ \\
\hline IL & Chicago & Cook & ORD & 6 & None reported \\
\hline GA & Atlanta & Clayton & ATL & 7 & An. quadrimaculatus \\
\hline $\mathrm{TX}$ & Houston & Harris & IAH & 8 & $\begin{array}{l}\text { An. punctipennis, An. quadrimaculatus, } \\
\text { An.pseudopunctipennis, An. crucians }\end{array}$ \\
\hline $\mathrm{TX}$ & Dallas & Dallas**/Tarrant & DFW & 9 & $\begin{array}{l}\text { An. punctipennis, An. quadrimaculatus, } \\
\text { An. pseudopunctipennis, An. } \\
\text { crucians, An. crucians complex }\end{array}$ \\
\hline FL & Miami & Broward & FLL & 10 & $\begin{array}{l}\text { An. quadrimaculatus, An. crucians, An. } \\
\text { atropos }^{\dagger \dagger}\end{array}$ \\
\hline DC & $\begin{array}{l}\text { Washington } \\
\text { DC* }\end{array}$ & DC & IAD & 11 & An. punctipennis \\
\hline FL & Orlando & Orange & $\mathrm{MCO}$ & 13 & $\begin{array}{l}\text { An. punctipennis, An. quadrimaculatus, } \\
\text { An. crucians }\end{array}$ \\
\hline WA & Seattle & King & SEA & 14 & None reported \\
\hline $\mathrm{PA}$ & Philadelphia & Philadelphia & PHL & 16 & $\begin{array}{l}\text { An. punctipennis, An. quadrimaculatus, } \\
\text { An. crucians }\end{array}$ \\
\hline MI & Detroit & Wayne & DTW & 17 & An. punctipennis, An. quadrimaculatus \\
\hline $\mathrm{NC}$ & Charlotte & Mecklenburg & CLT & 19 & An. punctipennis, An. quadrimaculatus \\
\hline MN & Minneapolis & Hennepin & MSP & 20 & None reported \\
\hline $\mathrm{CO}$ & Denver & Denver & DEN & 21 & None reported \\
\hline GU & Tamuning & $* * *$ Guam & GUM & 22 & Unknown \\
\hline MD & Baltimore & Anne Arundel & BWI & 25 & $\begin{array}{l}\text { An. punctipennis, An. quadrimaculatus, } \\
\text { An. pseudopunctipennis, An. } \\
\text { crucians, An. bradleyi, An. crucians } \\
\text { complex }\end{array}$ \\
\hline FL & Tampa & Hillsborough & TPA & 27 & None reported \\
\hline TX & Houston & Harris & $\mathrm{HOU}$ & 29 & $\begin{array}{l}\text { An. punctipennis, An. quadrimaculatus, } \\
\text { An.pseudopunctipennis, An. crucians }\end{array}$ \\
\hline IL & Chicago & Cook & MDW & 34 & None reported \\
\hline GU & Saipan & $* * *$ Guam & SPN & 35 & Unknown \\
\hline $\mathrm{TX}$ & Austin & Travis & AUS & 36 & $\begin{array}{l}\text { An. punctipennis, An. quadrimaculatus, } \\
\text { An.pseudopunctipennis, An. crucians }\end{array}$ \\
\hline $\mathrm{TX}$ & San Antonio & Bexar & SAT & 38 & $\begin{array}{l}\text { An. punctipennis, An. quadrimaculatus, } \\
\text { An.pseudopunctipennis, An. crucians }\end{array}$ \\
\hline $\mathrm{NC}$ & Raleigh/Durham & Wake & RDU & 39 & An. punctipennis, An. quadrimaculatus \\
\hline FL & Fort Myers & Lee & RSW & 40 & $\begin{array}{l}\text { An. quadrimaculatus, An. crucians, An. } \\
\text { atropos }{ }^{\dagger \dagger \dagger}\end{array}$ \\
\hline
\end{tabular}

*Washington DC airports are both located in Virginia, and there is technically not a county for these regions **Dallas/Fort Worth International Airport is straddling the Dallas and Tarrant county line; species recorded in both counties are listed here

$* * *$ Guam does not have any official counties, this territory is regarded as one county

$\dagger$ Airport rank indicates the US Department of Transportation's ranking among the Top 40: the smaller the number, the higher the number of international passengers traveling through the airport

${ }^{\dagger}$ Species presence data provided through personal communication (I. Unlu)

${ }^{\dagger \dagger}$ Species presence data provided through personal communication (Lee County Mosquito Control District)

States with additional airports in the US Top 40 International Air Passenger and Freight airports which do not report Anopheles spp. to MosquitoNET include AZ, NY, CA, NJ, MA, HI, NV, UT, OR, and PR outbreak preparedness, and none received NACCHO ranks of 1, which indicate full competence. Georgia, Maryland, Pennsylvania, New Jersey, New York, and Virginia have large international gateways, high numbers of imported malaria cases, multiple Anopheles species that can transmit Plasmodium, and suboptimal preparedness for vector-borne 
Table 3 Overall risk factors for malaria by state

\begin{tabular}{|c|c|c|c|c|c|c|}
\hline State & $\begin{array}{l}\text { \# annual } \\
\text { malaria cases } \\
(2016)\end{array}$ & $\begin{array}{l}\text { \# annual malaria } \\
\text { cases (5-year avg) }\end{array}$ & $\begin{array}{l}\text { \# malaria-vectoring } \\
\text { Anopheles spp. } \\
\text { (reported) }\end{array}$ & $\begin{array}{l}\text { \# malaria-vectoring } \\
\text { Anopheles spp. } \\
\text { (historical }^{\dagger} \text { ) }\end{array}$ & $\begin{array}{l}\text { \# passengers through } \\
\text { airports in US Top } 40 \\
\text { gateways }\end{array}$ & $\begin{array}{l}\text { Vector-borne disease } \\
\text { outbreak NACCHO } \\
\text { rank* }\end{array}$ \\
\hline AL & 9 & 10.6 & 5 & 4 & - & 4 \\
\hline $\mathrm{AK}$ & 2 & 4.4 & 4 & - & - & 5 \\
\hline $\mathrm{AZ}$ & 40 & 27.0 & - & 1 & $2,074,481$ & 4 \\
\hline $\mathrm{AR}$ & 5 & 6.0 & - & 4 & - & 5 \\
\hline $\mathrm{CA}$ & 125 & 118.2 & - & 2 & $43,302,579$ & 2 \\
\hline $\mathrm{CO}$ & 28 & 29.8 & 1 & 2 & $2,993,941$ & 5 \\
\hline $\mathrm{CT}$ & 17 & 16.6 & - & 3 & - & 5 \\
\hline DC & 25 & 19.0 & 1 & 3 & $9,224,597$ & - \\
\hline DE & 14 & 7.0 & - & 4 & - & 1 \\
\hline FL & 79 & 77.0 & 4 & 4 & $37,465,037$ & 2 \\
\hline GA & 69 & 77.6 & 3 & 4 & $12,223,120$ & 4 \\
\hline HI & 1 & 3.2 & - & - & $5,303,138$ & 1 \\
\hline ID & 3 & 4.6 & 2 & 2 & - & 3 \\
\hline IL & 65 & 61.0 & 2 & 3 & $14,401,498$ & 4 \\
\hline IN & 18 & 17.4 & 3 & 3 & - & 4 \\
\hline IA & 23 & 18.4 & 3 & 3 & - & 5 \\
\hline $\mathrm{KS}$ & 11 & 9.4 & - & 4 & - & 5 \\
\hline KY & 17 & 15.4 & - & 3 & - & 5 \\
\hline LA & 14 & 12.4 & - & 5 & - & 1 \\
\hline $\mathrm{ME}$ & 9 & 8.4 & - & 2 & - & 5 \\
\hline MD & 182 & 147.4 & 4 & 4 & - & 5 \\
\hline MA & 95 & 75.2 & - & 3 & $7,338,653$ & 2 \\
\hline MI & 46 & 29.6 & 2 & 3 & $3,745,832$ & 3 \\
\hline $\mathrm{MN}$ & 66 & 55.8 & 1 & 2 & $2,997,221$ & 3 \\
\hline MS & 8 & 3.0 & 4 & 5 & - & 5 \\
\hline MO & 20 & 17.6 & 4 & 4 & - & 5 \\
\hline MT & 5 & 2.2 & - & 2 & - & 3 \\
\hline NE & 6 & 6.8 & 2 & 2 & - & 5 \\
\hline NV & 7 & 7.0 & - & 1 & $3,683,113$ & 2 \\
\hline $\mathrm{NH}$ & 14 & 9.2 & - & 2 & - & 3 \\
\hline NJ & 86 & 91.6 & 2 & 4 & - & 3 \\
\hline NM & 3 & 3.0 & 2 & 3 & - & 3 \\
\hline NY & 339 & 296.4 & - & 3 & $49,927,217$ & 4 \\
\hline $\mathrm{NC}$ & 52 & 40.4 & 4 & 4 & $3,677,603$ & 4 \\
\hline ND & 7 & 4.8 & - & 2 & - & 4 \\
\hline $\mathrm{OH}$ & 63 & 44.8 & 3 & 3 & - & 4 \\
\hline OK & 8 & 11.2 & 2 & 4 & - & 4 \\
\hline OR & 21 & 20.2 & - & 2 & 858,354 & 2 \\
\hline PA & 84 & 73.6 & 3 & 3 & $3,919,874$ & 5 \\
\hline RI & 12 & 14.8 & 3 & 3 & - & 5 \\
\hline $\mathrm{SC}$ & 15 & 8.4 & 3 & 4 & - & 5 \\
\hline SD & 4 & 4.6 & 2 & 2 & - & 5 \\
\hline $\mathrm{TN}$ & 26 & 22.2 & 4 & 4 & - & 3 \\
\hline $\mathrm{TX}$ & 170 & 115.6 & 6 & 7 & $21,135,954$ & 2 \\
\hline UT & 9 & 7.2 & - & 1 & 993,506 & 2 \\
\hline VT & 6 & 5.2 & - & 2 & - & 5 \\
\hline VA & 75 & 77.4 & - & 4 & - & 3 \\
\hline
\end{tabular}


Table 3 (continued)

\begin{tabular}{lllllll}
\hline $\begin{array}{l}\text { State \# annual } \\
\text { malaria cases } \\
(2016)\end{array}$ & $\begin{array}{l}\text { \# annual malaria } \\
\text { cases (5-year avg) }\end{array}$ & $\begin{array}{l}\text { \# malaria-vectoring } \\
\text { Anopheles spp. } \\
\text { (reported) }\end{array}$ & $\begin{array}{l}\text { \# malaria-vectoring } \\
\text { Anopheles spp. } \\
\left.\text { (historical }^{\dagger}\right)\end{array}$ & $\begin{array}{l}\text { \# passengers through } \\
\text { airports in US Top 40 } \\
\text { gateways }\end{array}$ & $\begin{array}{l}\text { Vector-borne disease } \\
\text { outbreak NACCHO } \\
\text { rank* }\end{array}$ \\
\hline WA & 44 & 33.6 & 2 & 2 & $5,303,138$ & 3 \\
WV & 2 & 3.4 & 3 & 2 & - & 5 \\
WI & 21 & 14.0 & 2 & 3 & - & 3 \\
WY & 5 & 2.0 & - & 2 & - & 3 \\
GU & 0 & 0.0 & Unknown & - & $3,160,468$ & - \\
PR & 3 & 3.0 & - & - & 858,824 & - \\
VI & 0 & 0.2 & - & - & - & - \\
\hline
\end{tabular}

*NACCHO rank: 1 being the most prepared (all vector control programs meet core competencies), 5 being the least (all vector control programs in the state do not meet all core competencies)

${ }^{\dagger}$ Historical indicates mosquito species distributions published by Darsie and Ward (1981)

disease outbreaks, increasing their vulnerability for locally acquired malaria outbreaks. California, Massachusetts, and Florida had similar levels of risk, but relatively higher capacity for vector-borne disease outbreak preparedness.

Our review has several limitations including the lack of additional data sources to inform our assessment of risk and no statistical analyses were conducted. Additional sources of information important for malaria transmission include an examination of the seasonality of Anopheles mosquitoes and volume of international travel, the abundance of Anopheles mosquitoes in each area, blood feeding patterns, and the presence of appropriate habitat. Travel patterns including numbers of travelers from specific malarious countries could help further elucidate malaria risk exposure. In addition, the NACCHO vector-borne disease preparedness evaluation is based on the assessment of competencies and equally weighted them. For example, a vector control organization that does not perform routine surveillance (but does perform all other four core competencies) is considered at the same level as an organization that does not perform pesticide resistance testing but does meet each other core competency [33••]. This is a relatively subjective scale, and a weighted scale might have more utility when determining malaria transmission risk potential.

As climate change continues to impact temperature, rainfall, and other environmental factors globally, the distribution and abundance of malaria vectors will also be impacted. Increasingly warmer temperatures for longer periods of time will lengthen anopheline survival time and facilitate the development of Plasmodium sporozoites in the mosquitoes, thereby increasing the likelihood for infective mosquitoes $[27,36,37]$. On the contrary, shrinking swampy habitatsideal for some mosquito species including some Anophelesmay also have a protective impact on transmission dynamics. With the continued transmission of malaria globally and in Sub-Saharan Africa and increasing international travel and population movement, the risk of importation remains [36, 38]. Further complicating the issue, roughly two-thirds of residents in the USA (with known travel history and chemoprophylaxis status) who import malaria into the country report not taking prophylaxis, indicating the need for a behavioral change [39]. Insecticide and drug resistance from Anopheles mosquitoes and the Plasmodium parasite, respectively, will also play an important role in the future of this disease.

\section{Conclusion}

The increasing emergence and re-emergence of infectious diseases point to weak surveillance systems, and the presence of subpar public health infrastructures warrants a greater need to detect and respond to these health threats globally. The current coronavirus (COVID-19) pandemic has highlighted deficiencies in outbreak preparedness and underscored the need to prioritize local, state, and national efforts to prevent and control emerging and re-emerging disease threats globally. The current pandemic has implications for risk of malaria importation in the USA. Measures to mitigate COVID-19 transmission such as travel restrictions and lockdowns across many malaria-endemic countries are likely to reduce international travel and lessen the risk of importation in the near future. However, the long-term impact of the pandemic on human population movement and exposure to mosquitoes is unclear. For example, have levels and patterns of outdoor activities changed and have individuals increased or decreased their outdoor activities during the pandemic, and will this be reflected in communicable disease trends? Nevertheless, malaria continues to pose a public health threat in non-endemic regions like the USA. Improving outbreak preparedness for malaria and other emerging infectious disease threats is critical to global health security. 
Acknowledgments The authors would like to thank Dr. Roxanne Connelly, PhD, BCE from the Arboviral Diseases Branch, Division of Vector-Borne Diseases at CDC, for providing the MosquitoNET Anopheles data and Dr. Isik Unlu from Miami-Dade County Mosquito Control Division and Lee County Mosquito Control District for providing confirmation of Anopheles spp. collected in their respective counties. In addition, thanks to M. Katie Lynn, MS for providing editorial and structural comments for the construction of the manuscript.

\section{Compliance with Ethical Standards}

Conflict of Interest The authors declare that they have no conflict of interest.

Human and Animal Rights and Informed Consent This article does not contain any studies with human or animal subjects performed by any of the authors.

\section{References}

Papers of particular interest, published recently, have been highlighted as:

- Of importance

- Of major importance

1. Foster WA, Walker ED. Mosquitoes (Culicidae). Medical and veterinary entomology. Elsevier; 2019. p. 261-325.

2. Leventhal R, Cheadle RF. Medical parasitology: a self-instructional text. FA Davis Company; 2019.

3. World Health Organization. Malaria. 2020. https://www.who.int/ en/news-room/fact-sheets/detail/malaria. Accessed 29 Jul 2020.

4. Mace KE. Malaria surveillance-United States, 2016. Morb Mortal Wkly Rep. 2019;68:1-35.

5. Dye-Braumuller K, Fredregill C, Debboun M. Mosquito control. Mosquitoes, communities, and public health in Texas. Elsevier; 2020. p. 249-278.

6. Andrews JM. The eradication program in the USA. J Natl Malar Soc. 1951;10:99-123.

7. Bradley G. A review of malaria control and eradication in the United States. Mosquito News. 1966;26(Dec):462-70.

8. Russell PF. The United States and malaria: debits and credits. Bull N Y Acad Med. 1968;44(6):623-53.

9. Zucker JR. Changing patterns of autochthonous malaria transmission in the United States: a review of recent outbreaks. Emerg Infect Dis. 1996;2(1):37-43.

10. Darsie Jr RF, Ward RA. Identification and geographical distribution of the mosquitoes of North America, north of Mexico. Walter Reed Army Institute of Research, Washington DC; 1981. University Press of Florida; 2005.

11. Burkett-Cadena ND. Mosquitoes of the southeastern United States. University of Alabama Press; 2013.

12. Sinka ME, Rubio-Palis Y, Manguin S, Patil AP, Temperley WH, Gething PW, et al. The dominant Anopheles vectors of human malaria in the Americas: occurrence data, distribution maps and bionomic précis. Parasit Vectors. 2010;3(1):72.

13. Centers for Disease Control and Prevention. Local transmission of Plasmodium vivax malaria-Virginia, 2002. Morb Mortal Wkly Rep. 2002;51(41):921.

14. Centers for Disease Control and Prevention. Probable locally acquired mosquito-transmitted Plasmodium vivax infection-Suffolk
County, New York, 1999. Morb Mortal Wkly Rep. 2000;49(22): 495.

15. Centers for Disease Control and Prevention. Multifocal autochthonous transmission of malaria-Florida, 2003. Morb Mortal Wkly Rep. 2004;53(19):412.

16. Sunstrum J, Elliott LJ, Barat LM, Walker ED, Zucker JR. Probable autochthonous Plasmodium vivax malaria transmission in Michigan: case report and epidemiological investigation. Am J Tropi Med Hyg. 2001;65(6):949-53.

17. Malecki J, Kumar S, Johnson B, Gidley M. Local transmission of Plasmodium vivax malaria-Palm Beach County, Florida, 2003. Morb Mortal Wkly Rep. 2003;52(38):908-11.

18. Mace KE, Arguin PM, Tan KR. Malaria surveillance-United States, 2015. Morb Mortal Wkly Rep. 2018;67(7):1.

19. Mace KE, Arguin PM. Malaria surveillance-United States, 2014. Morb Mortal Wkly Rep: Surveillance Summaries (Washington, DC: 2002). 2017;66(12):1-24.

20. Cullen KA, Arguin PM. Malaria surveillance-United States, 2012. Morb Mortal Wkly Rep: Surveillance Summaries. 2014;63(12):1-22.

21. Cullen KA, Arguin PM. Malaria surveillance-United States, 2011. Morb Mortal Wkly Rep: Surveillance Summaries. 2013;62(5):1-17.

22. Centers for Disease Control and Prevention. Simian malaria in a US traveler-New York, 2008. Morb Mortal Wkly Rep. 2009;58(9):229.

23. Wilson ME, Kantele A, Jokiranta TS. Review of cases with the emerging fifth human malaria parasite, Plasmodium knowlesi. Clin Infect Dis. 2011;52(11):1356-62.

24. Filler SJ, MacArthur JR, Parise M, Wirtz R, Eliades MJ, Dasilva A, Steketee R. Locally acquired mosquito-transmitted malaria: a guide for investigations in the United States. 2006. Filler et al. describe guidelines for moquito control organiations and health departments to handle locally acquired malaria outbreaks.

25. Isaäcson M. Airport malaria: a review. Bull World Health Organ. 1989;67(6):737-43.

26. Castelli F, Caligaris S, Matteelli A, Chiodera A, Carosi G, Fausti G. Baggage malaria' in Italy: cryptic malaria explained? Trans R Soc Trop Med Hyg. 1993;87(4):394.

27. Robert LL, Santos-Ciminera PD, Andre RG, Schultz GW, Lawyer PG, Nigro J, et al. Plasmodium-infected Anopheles mosquitoes collected in Virginia and Maryland following local transmission of Plasmodium vivax malaria in Loudoun County, Virginia. J Am Mosq Control Assoc. 2005;21(2):187-93.

28. Khuu D, Eberhard ML, Bristow BN, Javanbakht M, Ash LR, Shafir $\mathrm{SC}$, et al. Economic impact of malaria-related hospitalizations in the United States, 2000-2014. J Infect Public Health. 2019;12(3):42433.

29. Rosenthal PJ, Tan KR. Expanded availability of intravenous artesunate for the treatment of severe malaria in the United States. Am JTrop Med Hyg. 2019;100(6):1295-6.

30. Haston JC, Hwang J, Tan KR. Guidance for using tafenoquine for prevention and antirelapse therapy for malaria-United States, 2019. Morb Mortal Wkly Rep. 2019;68(46):1062-8.

31. US International Air Passenger and Freight Statistics for June 2019. In: United States Department of Transportation, editor. 2020. p. 37.

32. Levine RS, Peterson AT, Benedict MQ. Distribution of members of Anopheles quadrimaculatus Say sl (Diptera: Culicidae) and implications for their roles in malaria transmission in the United States. J Med Entomol. 2004;41(4):607-13.

33.・ National Association of County and City Health Officials. Mosquito control capablities in the U.S. 2017. https://www. naccho.org/uploads/downloadable-resources/Mosquito-control-inthe-U.S.-Report.pdf. Accessed 6 Aug 2020. This NACCHO survey is the first national survey to attempt to evaluate preapredness for vector-borne disease outbreaks, which is crucial to this article. 
34. Almeida APG, Fouque F, Launois P, Sousa CA, Silveira H. From the laboratory to the field: updating capacity building in medical entomology. Trends Parasitol. 2017;33(9):664-8.

35. Fernandes JN, Moise IK, Maranto GL, Beier JC. Revamping mosquito-borne disease control to tackle future threats. Trends Parasitol. 2018;34(5):359-68.

36. McCord GC. Malaria ecology and climate change. Eur Phys J Special Top. 2016;225(3):459-70.

37. Berrang-Ford L, MacLean J, Gyorkos TW, Ford J, Ogden N. Climate change and malaria in Canada: a systems approach. Interdisc Perspect Infect Diseases. 2009;2009:1-13.
38. Caminade C, McIntyre KM, Jones AE. Impact of recent and future climate change on vector-borne diseases. Ann N Y Acad Sci. 2019;1436(1):157-73.

39. McCarthy M. US malaria patients have often not taken chemoprophylactic drugs, CDC report finds. Br Med J. Publishing Group. 2014;349:g7462.

Publisher's Note Springer Nature remains neutral with regard to jurisdictional claims in published maps and institutional affiliations. 